\title{
“ACHO QUE EDUCAR É COMO CATAR PIOLHO NA CABEÇA DE CRIANÇA": REFLEXÕES SOBRE A LITERATURA INDÍGENA EM PROVAS DO ENEM
}

\section{Creo que Educar Es Como Recoger Piojos en la Cabeza de Niños: Reflexiones sobre la Literatura Indígena en las Pruebas de ENEM}

\author{
Jairo da Silva e Silva ${ }^{1}$
}

\begin{abstract}
Resumo: O presente artigo versa sobre as dinâmicas de aplicabilidade da Lei $\mathrm{n}^{\circ} 11.645 / 08$, a qual estabelece as diretrizes e bases da educação nacional quanto à inclusão no currículo oficial da rede de ensino e a obrigatoriedade da temática "História e cultura afro-brasileira e indígena". A referida lei prevê que os conteúdos referentes à histórias e culturas destes povos devem ser ministrados no âmbito de todo o currículo escolar, mas com especial atenção nas áreas de artes, história e literatura brasileiras. Portanto, neste trabalho, de abordagem qualitativa com procedimentos da pesquisa documental, objetivamos discorrer sobre a presença da literatura indígena no Exame Nacional do Ensino Médio (Enem) desde o advento da lei em questão, no de 2008, até a edição mais atual, neste caso, ano 2019. Com o foco de atenção nos itens que consideram a textualidade como fato literário, investigamos as 400 questões de literatura presentes nas 24 provas da área de conhecimento "Linguagens, Códigos e suas Tecnologias" dos últimos 12 anos do Enem e procuramos analisar de que maneira a literatura escrita por autoras/es indígenas se materializa no exame de seleção para a maioria das universidades públicas brasileiras. Os resultados apontam que a baixa presença da escrita literária indígena no Enem revela o quanto a escola prescinde a esta literatura.
\end{abstract}

Palavras-chave: Lei $n^{\circ}$ 11.645/08. Literatura Indígena. Enem.

Resumen: Este artículo trata sobre la dinámica de aplicabilidad de la Ley $\mathrm{n}^{\circ} 11.645 / 08$, que establece los lineamientos y bases de la educación nacional en cuanto a la inclusión en el currículo oficial de la red educativa y el tema obligatorio "Historia y cultura afrobrasileña e indígena". Esta ley establece que los contenidos referentes a las historias y culturas de estos pueblos deben enseñarse dentro de todo el currículo escolar, pero con especial atención en las áreas de las artes, la historia y la literatura brasileñas. Por ello, en este trabajo, con un enfoque cualitativo con procedimientos de investigación documental, pretendemos discutir la presencia de la literatura indígena en el Examen Nacional de Bachillerato (Enem) desde el advenimiento de la ley en cuestión, en 2008, hasta la edición más actual, en este caso, año 2019. Con el foco en los ítems que consideran la textualidad como un hecho literario, investigamos las 400 preguntas de literatura presentes en las 24 pruebas en el área de conocimiento "Idiomas, Códigos y sus Tecnologías" de los últimos 12 años de Enem y buscamos analizar cómo la literatura escrita por autoras/es indígenas se materializa en el examen de selección de la mayoría de las universidades públicas brasileñas. Los resultados muestran que la baja presencia de escritura literaria indígena en Enem revela cuánto la escuela prescinde de esta literatura.

Palabras-clave: Ley $n^{\circ}$ 11.645/08. Literatura Indígena. Enem.

\footnotetext{
${ }^{1}$ Professor na área de Letras no Instituto Federal do Pará (IFPA/Abaetetuba). Mestre em Letras pela Universidade Federal do Pará (UFPA). Doutorando em Letras: Linguagens e Representações pela Universidade Estadual de Santa Cruz (UESC, Ilhéus/BA). ORCID: https://orcid.org/0000-0003-0427-7237. E-mail: jairo.silva@ifpa.edu.br.
} 


\section{Introdução}

Neste trabalho, discorremos sobre a natureza constitutiva da literatura indígena (escrita por pessoas indígenas) e seu contributo junto às discussões sobre as literaturas impulsionadas no país mediante o advento da Lei $\mathrm{n}^{\circ} 11.645 / 08$ (BRASIL, 2008). Lei esta que estabelece as diretrizes e bases da educação nacional no tocante à inclusão no currículo oficial da rede de ensino a obrigatoriedade da temática "História e cultura afro-brasileira e indígena", sendo, portanto, responsabilidade da escola efetivá-la em todo o currículo, mas com atenção especial às áreas temáticas de artes, história e literatura brasileiras.

Assim, este estudo bibliográfico ${ }^{2}$ e com técnicas da pesquisa documental ${ }^{3}$ tem como foco a literatura indígena e a sua aplicabilidade, neste caso, não no currículo escolar propriamente dito, mas na prova do Exame Nacional do Ensino Médio (doravante, Enem). Organizado e executado anualmente pelo Ministério da Educação (MEC), o Enem tem por objetivo avaliar a qualidade do ensino médio das escolas de todo o país e serve como processo seletivo para acesso a $90 \%$ das instituições de ensino superior no Brasil, além de ser o meio pelo o qual estudantes de baixa renda conseguem participar de programas governamentais que concedem bolsas de estudo ou financiamento a juros baixos em instituições privadas.

Para o empreendimento proposto, realizamos uma investigação em todas as provas do Enem aplicadas desde a sanção à Lei $\mathrm{n}^{\circ} 11.645$, em março de 2008, até à edição mais atual, no ano de 2019. Tomando como recorte a produção literária de escritoras/es indígenas, debruçamos especial atenção às 400 questões de literatura presentes nas 24 provas da área de conhecimento "Linguagens, Códigos e suas Tecnologias", buscando evidenciar como ocorre a presença da literatura indígena neste importante exame de projeção nacional.

Quanto à organização, além desta parte introdutória, onde tecemos as questões norteadoras e o percurso metodológico, este artigo está organizado em três outras seções e as considerações finais. Na segunda parte, intitulada "Considerações sobre a literatura indígena e seu lugar na escola", de forma breve, porém necessária, pontuamos algumas questões teóricas que constituem a literatura indígena e a sua relação com as práticas escolares. Na terceira seção, intitulada "A literatura no Enem: indispensáveis considerações" adentramos para além da conceituação e constituição do Enem, pois, apresentamos como destaque o estudo realizado sobre o lugar da textualidade literária neste exame, bem como a presença da literatura indígena nos últimos 12 anos. Na quarta parte, sob o título "Acho que educar é como catar piolho na cabeça de criança': análise da única questão que menciona um escritor indígena em provas do Enem (2008-2019)", realizamos as análises e os resultados a partir das questões que abordam a literatura indígena, com especial atenção à edição do ano 2017 a qual menciona o escritor Daniel Munduruku, comparando-a às demais questões de literatura daquela prova. Nas Considerações finais, expomos as principais constatações, ponderações e perspectivas.

\section{Considerações sobre a literatura indígena e seu lugar na escola}

Refletir sobre a literatura indígena é tentar compreender a produção literária de escritoras/es que pertencem a variadas etnias que compõem mais de 305 sociedades indígenas,

\footnotetext{
${ }^{2}$ Para Gil (2007, p. 44): “Os exemplos mais característicos de pesquisa bibliográfica são os de investigações sobre ideologias ou aquelas que se propõem à análise das diversas posições acerca de um problema".

3 Pesquisa documental "é aquela realizada a partir de documentos, contemporâneos ou retrospectivos, considerados cientificamente autênticos (não fraudados); tem sido largamente utilizada nas ciências sociais, na investigação histórica, a fim de descrever/comparar fatos sociais, estabelecendo suas características ou tendências" (PÁDUA, 1997, p. 62).
} 
falantes de mais de 270 línguas, segundo os dados do último censo realizado pelo Instituto Brasileiro de Geografia e Estatística (IBGE) no ano de 2010. Importa esclarecer que esta demarcação de literatura não deve ser confundida com literatura indianista e literatura indigenista.

A literatura indianista é uma referência ao movimento literário "Romantismo" brasileiro do século XIX ${ }^{4}$ de temática indígena, principalmente, a produção literária de Gonçalves Dias, e de José de Alencar. Assim, nas aulas de literatura brasileira, durante o ensino médio é ensinado a literatura indianista. Os trabalhos dos autores mencionados são apresentados com demasiada relevância para a construção da nacionalidade brasileira. A título de exemplo, eis um enunciado presente em um dos livros didáticos adotados em milhares de escolas públicas:

Gonçalves Dias, em sua poesia indianista, transformou o índio em um participante decisivo do processo de construção da identidade nacional. José de Alencar fez o mesmo em alguns de seus romances, de onde brotam, em meio à natureza exuberante, modelos heroicos de índios dos quais os brasileiros podiam descender com orgulho. (ABAURRE et al., 2010, p. 120).

Por outro lado, temos a literatura indigenista. Ao reler Romero (2010), esclarece-nos a pesquisadora Julie Dorrico (2018, p. 235-236) que se trata de autores que "não são indígenas, mas buscam compreender as cosmologias indígenas que estudam para dar a conhecer essas culturas à sociedade de um modo mais geral". No caso da literatura indígena, encontramos nas palavras da mencionada estudiosa sobre o assunto, a seguinte explicação:

\begin{abstract}
A literatura indígena brasileira desenvolvida a partir da década de 1990 é um dos fenômenos político-culturais mais importantes de nossa esfera pública e se insere nessa dinâmica ampla de ativismo, militância e engajamento de minorias historicamente marginalizadas e invisibilizadas de nossa sociedade, que assumem o protagonismo público, político e cultural enquanto núcleo de sua reafirmação como grupo-comunidade e, em consequência, de enfrentamento dessa situação de exclusão e violência vividas e sofridas. (DORRICO et al., 2018, p. 11).
\end{abstract}

Na prática, as propostas indianistas e indigenistas são literaturas que não dão conta de expressar a expressividade e real autenticidade dos diversos povos indígenas brasileiros. Amparadas pela lógica eurocêntrica, geralmente promove uma imagem distorcida, principalmente a indianista. É nessa condição que a literatura indígena se inscreve: em contraposição às práticas dominantes, desde então, várias/os indígenas brasileiras/os adotam estratégias de (re)construção das representações sociais de seus lugares de pertencimento na contemporaneidade; ou seja, entre essas estratégias, fazem uso da literatura como mecanismo de luta, conscientização (e ressignificação da identidade) entre variadas etnias indígenas, mas todas contra as insígnias identitárias impostas pelas marcas da colonialidade.

Segundo o escritor Daniel Munduruku, a produção literária indígena tem conquistado um espaço de visibilidade no cenário nacional, com centenas de títulos, em que, autoras/es lançam livros com certa regularidade. Muitas/os mantêm blogs, sites, perfis nas redes sociais. São sujeitos que têm protagonizado a escrita de suas próprias vivências e a realidade de suas etnias, que utilizam a escrita como uma "arma capaz de reverter situações de conflito, denunciar abusos internos e externos, mostrando que a literatura, seja ela entendida como se achar melhor, verdadeiramente, um novo instrumental utilizado pela cultura para atualizar a Memória ancestral" (MUNDURUKU, 2014, p. 181).

\footnotetext{
${ }^{4}$ O Romantismo representa um período de profusão de ideias políticas, sociais, culturais e artísticas que tomou conta da Europa nos séculos XVIII e XIX e expandiu-se pelo Brasil oitocentista, estendendo-se também para a literatura. (PONTES, 2018, p. 129).
} 
A literatura indígena contemporânea é um lugar utópico (de sobrevivência), uma variante do épico tecido pela oralidade; um lugar de confluência de vozes silenciadas e exiladas (escritas) ao longo dos mais de 500 anos de colonização. Enraizada nas origens, a literatura indígena contemporânea vem se preservando na auto-história de seus autores e autoras e na recepção de um público-leitor diferenciado, isto é, uma minoria que semeia outras leituras possíveis no universo de poema e prosas autóctones. (GRAÚNA, 2013, p. 15).

Portanto, no âmbito da literatura brasileira contemporânea, a produção literária de escritoras/es indígenas está em constante movimentação. É nessa esteira que tal literatura busca superar a fratura colonial e se inscreve sob uma escrita engendrada às suas peculiaridades quanto à forma de representar a realidade, bem como à forma de expressividade artística, sem abandonar, todavia, as dinâmicas da ancestralidade, e, principalmente, a (d)enunciação das barbáries impostas pelas marcas da colonização.

Quanto à presença no currículo escolar, a literatura indígena ganha lugar de obrigatoriedade a partir da Lei $\mathrm{n}^{\mathrm{o}} 11.645 / 08$, a qual obriga a oferta da temática "História e cultura afro-brasileira e indígena" no contexto da educação nacional. Assim rege tal lei: " $\$ 2^{\circ}$ Os conteúdos referentes à história e cultura afro-brasileira e dos povos indígenas brasileiros serão ministrados no âmbito de todo o currículo escolar, em especial nas áreas de educação artística e de literatura e história brasileiras". (BRASIL, 2008).

No caso da Base Nacional Comum Curricular (BNCC), em vários momentos a referida Lei é citada, mas quando se refere à área de Língua Portuguesa, no que diz respeito ao ensino fundamental, a única ocorrência que faz referência à literatura indígena é sobre as habilidades que se esperam das/os discentes do $6^{\circ}$ e $7^{\circ}$ anos desta etapa escolar:

Ler, de forma autônoma, e compreender - selecionando procedimentos e estratégias
de leitura adequados a diferentes objetivos e levando em conta características dos
gêneros e suportes -, romances infanto-juvenis, contos populares, contos de terror,
'lendas brasileiras, indígenas' e africanas, narrativas de aventuras, narrativas de
enigma, mitos, crônicas, autobiografias, histórias em quadrinhos, mangás, poemas de
forma livre e fixa (como sonetos e cordéis), vídeo-poemas, poemas visuais, dentre
outros, expressando avaliação sobre o texto lido e estabelecendo preferências por
gêneros, temas, autores. (BRASIL, 2017, p. 165). [Grifos nossos].

A BNCC de Língua Portuguesa para o ensino médio também cita a Lei n ${ }^{\circ} 11.645 / 08$ por diversas vezes e prevê que: "em relação à literatura, a leitura do texto literário, que ocupa o centro do trabalho no Ensino Fundamental, deve permanecer nuclear também no Ensino Médio" (BRASIL, 2017, p. 491). Neste sentido, o documento destaca, ainda, quatro ocorrências sobre a literatura indígena, principalmente no que tange à progressão das aprendizagens e habilidades do alunado, que, entre outras medidas, deve ser levado em consideração [com grifos nossos]:

A inclusão de obras da tradição literária brasileira e de suas referências ocidentais em especial da literatura portuguesa -, assim como obras mais complexas da literatura contemporânea e das 'literaturas indígena', africana e latino-americana. (BRASIL, 2017, p. 492).

No Ensino Médio, devem ser introduzidas para fruição e conhecimento, ao lado da literatura africana, afro-brasileira, 'indígena' e da literatura contemporânea, obras da tradição literária brasileira e de língua portuguesa, de um modo mais sistematizado, em que sejam aprofundadas as relações com os períodos históricos, artísticos e culturais. (BRASIL, 2017, p. 513).

Diversificar, ao longo do Ensino Médio, produções das culturas juvenis contemporâneas (slams, vídeos de diferentes tipos, playlists comentadas, raps e outros gêneros musicais etc.), minicontos, nanocontos, best-sellers, literatura juvenil 
brasileira e estrangeira, incluindo entre elas a literatura africana de língua portuguesa, a afro-brasileira, a latino-americana etc., obras da tradição popular (versos, cordéis, cirandas, canções em geral, contos folclóricos de matrizes europeias, africanas, 'indígenas' etc.) que possam aproximar os estudantes de culturas que subjazem na formação identitária de grupos de diferentes regiões do Brasil. (BRASIL, 2017, p. 514).

Analisar obras significativas da 'literatura brasileira' e da literatura de outros países e povos, em especial a portuguesa, a 'indígena', a africana e a latino-americana, com base em ferramentas da crítica literária (estrutura da composição, estilo, aspectos discursivos), considerando o contexto de produção (visões de mundo, diálogos com outros textos, inserções em movimentos estéticos e culturais etc.) e o modo como elas dialogam com o presente. (BRASIL, 2017, p. 516).

A partir desta inscrição, as instituições públicas e privadas, em nível nacional vêm organizando a seus respectivos currículos conforme tais diretrizes. Portanto, a questão da presença do texto literário indígena na sala de aula, depende de diversos fatores que variam de acordo com a realidade de cada estabelecimento de ensino. No caso da instituição de nossa atuação profissional, uma unidade da Rede Federal de Educação Profissional, Científica e Tecnológica, localizada na Amazônia brasileira, que oferta o ensino médio integrado a variados cursos técnicos profissionalizantes, as temáticas sobre a literatura indígena são programadas para ocorrer nas turmas de $2^{\circ}$ ano, em ocasião das aulas de "Romantismo", no tocante às questões indianistas. Ganha destaque, ainda, no $3^{\circ}$ ano, nas aulas sobre "Pré-modernismo" e "Modernismo" brasileiro; por fim, consta na seção referente às "Tendências das Literaturas Contemporâneas".

Desta forma, o ensino médio é considerado importante etapa para a vida da/o estudante secundária/o, pois, além de conferir a conclusão da educação básica, é o caminho para a ascensão ao ensino superior, e, geralmente, isso se dá mediante a realização do Exame Nacional do Ensino Médio, o Enem. Portanto, após a compreensão sobre as distinções entre as noções de literatura indianista, indigenista e indígena, e como deve ocorrer no âmbito escolar, na seção seguinte, adentramos nas dinâmicas que constituem o Enem e como a textualidade literária se faz presente neste exame; oportunamente, verificamos como se materializa a presença da literatura indígena nos últimos 12 anos de aplicação desta prova.

\section{A literatura no Enem: indispensáveis considerações}

Realizado anualmente pelo Instituto Nacional de Estudos e Pesquisas Educacionais Anísio Teixeira (Inep) e MEC, o Enem tem como finalidade principal a avaliação do desempenho escolar e acadêmico ao fim do ensino médio. Neste ano, $2020^{5}$, se completa 22 anos desde a primeira aplicação, em 1998. Este exame tem passado por diversas alterações tanto na sua estrutura, quanto em seus objetivos. Ao realizar uma comparação entre os objetivos desde a primeira edição (1998) e 22 anos depois (2020), percebemos as transformações:

I. Conferir ao cidadão parâmetro para autoavaliação, com vistas da continuidade de sua formação e sua inserção no mercado de trabalho;

II. Criar referência nacional para os egressos de qualquer das modalidades do ensino médio;

III. Fornecer subsídios às diferentes modalidades de acesso à educação superior;

IV. Constituir-se em modalidade de acesso a cursos profissionalizantes pós-médio. (BRASIL, 1998, p. 05).

\footnotetext{
${ }^{5}$ Em função do impacto da pandemia (coronavírus), a aplicação da edição de 2020 foi adiado para janeiro de 2021.
} 
Em 2020, o edital prevê como "principal finalidade a avaliação individual do desempenho do participante ao final do ensino médio", em que os resultados devem possibilitar:

2.2.1 a constituição de parâmetros para a autoavaliação do participante, com vistas à continuidade de sua formação e a sua inserção no mercado de trabalho;

2.2.2 a criação de referência nacional para o aperfeiçoamento dos currículos do ensino médio;

2.2.3 a utilização do Exame como mecanismo único, alternativo ou complementar para acesso à educação superior, especialmente a ofertada pelas instituições federais de educação superior;

2.2.4 o acesso a programas governamentais de financiamento ou apoio ao estudante da educação superior;

2.2.5 a sua utilização como instrumento de seleção para ingresso nos diferentes setores do mundo do trabalho; e

2.2.6 o desenvolvimento de estudos e indicadores sobre a educação brasileira.

(BRASIL, 2020a, p. 34).

Os objetivos foram (re)elaborados conforme as condições de produções históricas dos governos nos últimos 22 anos, compostos pelas gestões presidenciais de Fernando Henrique Cardoso (1995-1998, 1999-2002), Luís Inácio Lula da Silva (2003-2006, 2007-2010), Dilma Vana Rousseff (2011-2014, 2015-2016), Michel Miguel Elias Temer Lulia (2017-2018) e Jair Messias Bolsonaro (2019-atual).

$\mathrm{Na}$ atualidade, o exame é constituído por 180 questões distribuídas em quatro provas objetivas e uma redação dissertativa. Cada prova objetiva possui 45 questões de múltipla escolha e procura avaliar as seguintes áreas de conhecimento do ensino médio e os respectivos componentes curriculares: Linguagens, Códigos e suas Tecnologias e Redação: Língua Portuguesa, Literatura, Língua Estrangeira (Inglês ou Espanhol), Artes, Educação Física e Tecnologias da Informação e Comunicação; Ciências Humanas e suas Tecnologias: História, Geografia, Filosofia e Sociologia; Ciências da Natureza e suas Tecnologias: Química, Física e Biologia; e Matemática e suas Tecnologias: Matemática. (BRASIL, 2020a).

Neste sentido, debruçamos a nossa atenção às questões de literatura, foco de análise deste trabalho. Conforme a Matriz de Referência do Enem, as 45 questões da prova de Linguagens, Códigos e suas Tecnologias objetivam avaliar nove competências. Porém, é a quinta competência que trata exclusivamente da textualidade literária, em que se pretende: "analisar, interpretar e aplicar recursos expressivos das linguagens, relacionando textos com seus contextos, mediante a natureza, função, organização, estrutura das manifestações, de acordo com as condições de produção e recepção" (BRASIL, 2020b, p. 03).

Para que se cumpra tal objetivo, exige-se o desenvolvimento de pelo menos três habilidades: estabelecer relações entre o texto literário e o momento de sua produção, situando aspectos do contexto histórico, social e político; relacionar informações sobre concepções artísticas e procedimentos de construção do texto literário; e reconhecer a presença de valores sociais e humanos atualizáveis e permanentes no patrimônio literário nacional. No tocante às questões de literatura, assim preconiza o documento:

Estudo do texto literário: relações entre produção literária e processo social, concepções artísticas, procedimentos de construção e recepção de textos:

produção literária e processo social; processos de formação literária e de formação nacional; produção de textos literários, sua recepção e a constituição do patrimônio literário nacional; relações entre a dialética cosmopolitismo/localismo e a produção literária nacional; elementos de continuidade e ruptura entre os diversos momentos da literatura brasileira; associações entre concepções artísticas e procedimentos de construção do texto literário em seus gêneros (épico/narrativo, lírico e dramático) e formas diversas.; articulações entre os recursos expressivos e estruturais do texto 
literário e o processo social relacionado ao momento de sua produção; representação literária: natureza, função, organização e estrutura do texto literário; relações entre literatura, outras artes e outros saberes. (BRASIL, 2020b, p. 15-16).

Desta forma, realizamos o levantamento de todas as provas do Enem desde a implementação da Lei $\mathrm{n}^{\circ} 11.645 / 08$ e encontramos pelo menos quatrocentas questões envolvendo a textualidade literária enquanto qualquer manifestação capaz de envolver a fruição estética (Tabela 1). Importa citar que, desde o ano 2010, o Enem passou a ser aplicado junto a um público com pouca visibilidade no que diz respeito aos diversos programas educacionais estatais: pessoas presas e jovens em medidas socioeducativas que fazem parte do sistema carcerário brasileiro. Trata-se da aplicação para pessoas privadas de liberdade, o Enem PPL, o qual passou a fazer parte da avaliação anual 12 anos depois da instituição do exame nacional, após o INEP levar em consideração a legislação da Portaria 807/10, que determina o direito de acesso à educação para todos, inclusive, para pessoas inseridas em unidades prisionais. Portanto, no levantamento realizado, contabilizamos o Enem PPL também, pois, é numa dessas provas que consta a única referência a um escritor indígena, isto é, no Enem PPL do ano de 2017.

Tabela 1 - Questões sobre literatura presentes nas provas do Enem (2008 a 2019).

\begin{tabular}{|c|c|c|c|}
\hline Ano & Modalidade de prova & Questões de literatura & Questões de literatura indígena \\
\hline 2008 & aplicação única & 07 & 02 questões sobre? \\
\hline 2009 & $1^{\mathrm{a}}$ aplicação & 22 & 0 \\
\hline 2009 & $2^{\mathrm{a}}$ aplicação ${ }^{6}$ & 22 & 0 \\
\hline 2010 & $1^{\mathrm{a}}$ aplicação & 14 & 0 \\
\hline 2010 & PPL & 17 & 0 \\
\hline 2011 & $1^{a}$ aplicação & 12 & 0 \\
\hline 2011 & PPL & 12 & 0 \\
\hline 2012 & $1^{\mathrm{a}}$ aplicação & 23 & 0 \\
\hline 2012 & PPL & 18 & 0 \\
\hline 2013 & $1^{\mathrm{a}}$ aplicação & 17 & 0 \\
\hline 2013 & PPL & 15 & 0 \\
\hline 2014 & $1^{\mathrm{a}}$ aplicação & 18 & 0 \\
\hline 2014 & PPL & 16 & 0 \\
\hline 2015 & $1^{a}$ aplicação & 17 & 1 questão feita por indigenista \\
\hline 2015 & PPL & 15 & 0 \\
\hline 2016 & $1^{\mathrm{a}}$ aplicação & 20 & 0 \\
\hline 2016 & $2^{\text {a }}$ aplicação ${ }^{7}$ & 14 & 0 \\
\hline 2016 & PPL & 18 & 0 \\
\hline 2017 & $1^{\mathrm{a}}$ aplicação & 16 & 0 \\
\hline 2017 & PPL & 19 & 01 \\
\hline 2018 & $1^{\mathrm{a}}$ aplicação & 15 & 0 \\
\hline 2018 & PPL & 17 & 0 \\
\hline 2019 & $1^{\mathrm{a}}$ aplicação & 17 & 0 \\
\hline 2019 & PPL & 19 & 0 \\
\hline & $\begin{array}{l}\text { Total de Provas } \\
\text { Aplicadas: } 24\end{array}$ & $\begin{array}{c}\text { Total de questões } \\
\text { de/sobre literatura: } 400\end{array}$ & $\begin{array}{l}\text { Total de questões de/sobre a } \\
\text { literatura indígena: } 04\end{array}$ \\
\hline
\end{tabular}

Fonte: elaboração própria a partir das provas aplicadas no período investigado.

\footnotetext{
${ }^{6}$ Em 2009, o vazamento da prova do Enem obrigou o Ministério da Educação a cancelar a prova e a remarcar o exame com dois meses de atraso após ser totalmente refeito.

${ }^{7}$ No ano de 2016, em virtude às ocupações de escolas e Instituições de Ensino Superior (IES) ocorridas entre os meses de outubro e novembro, foram necessárias três aplicações do Enem, e não duas como de costume.
} 
Desta forma, quando analisamos as 400 questões de/sobre literatura durante o período investigado (Gráfico 1), temos os seguintes dados:

a) Entre os 10 autores mais citados, apenas uma escritora aparece na relação, neste caso, Clarice Lispector, mencionada sete vezes, e, por ordem alfabética, consta na $6^{a}$ posição;

b) Em geral, Machado de Assis é o autor mais mencionado, com 12 ocorrências, seguido dos/a demais autores/a e suas respectivas menções: $2^{\circ}$ ) Carlos Drummond de Andrade - 10; $3^{\circ}$ ) Luís Fernando Veríssimo $-10 ; 4^{\circ}$ ) Guimarães Rosa $-9 ; 5^{\circ}$ ) Manuel Bandeira - 9; $6^{\circ}$ ) Clarice Lispector $-7 ; 7^{\circ}$ ) Graciliano Ramos - 7; $8^{\circ}$ ) Aluísio Azevedo - 6; $9^{\circ}$ ) João Cabral de Melo Neto; $10^{\circ}$ ) Mário de Andrade - 6. Ou seja, nem de longe, um/a escritor/a indígena configura nesta relação;

c) Entre as 400 questões de literatura, é feita apenas uma menção a um/a escritor indígena, neste caso, a Daniel Munduruku, na prova do Enem PPL 2017;

d) No rol desse quantitativo, identificamos pelo menos três questões de autoria não indígena, mas que tratam de aspectos da literatura indígena, a saber: na prova do ano da instituição da Lei $\mathrm{n}^{\circ} 11.645$, isto é, no ano de 2008, duas questões a partir de texto único intitulado "A Ema", no entanto sem mencionar a autoria das questões propostas. A outra ocorrência, aparece sete anos depois, elaborada pelo pesquisador indigenista Wilmar da Rocha D'Angelis.

Gráfico 1 - 400 questões sobre literatura presentes nas provas do Enem (2008 a 2019).

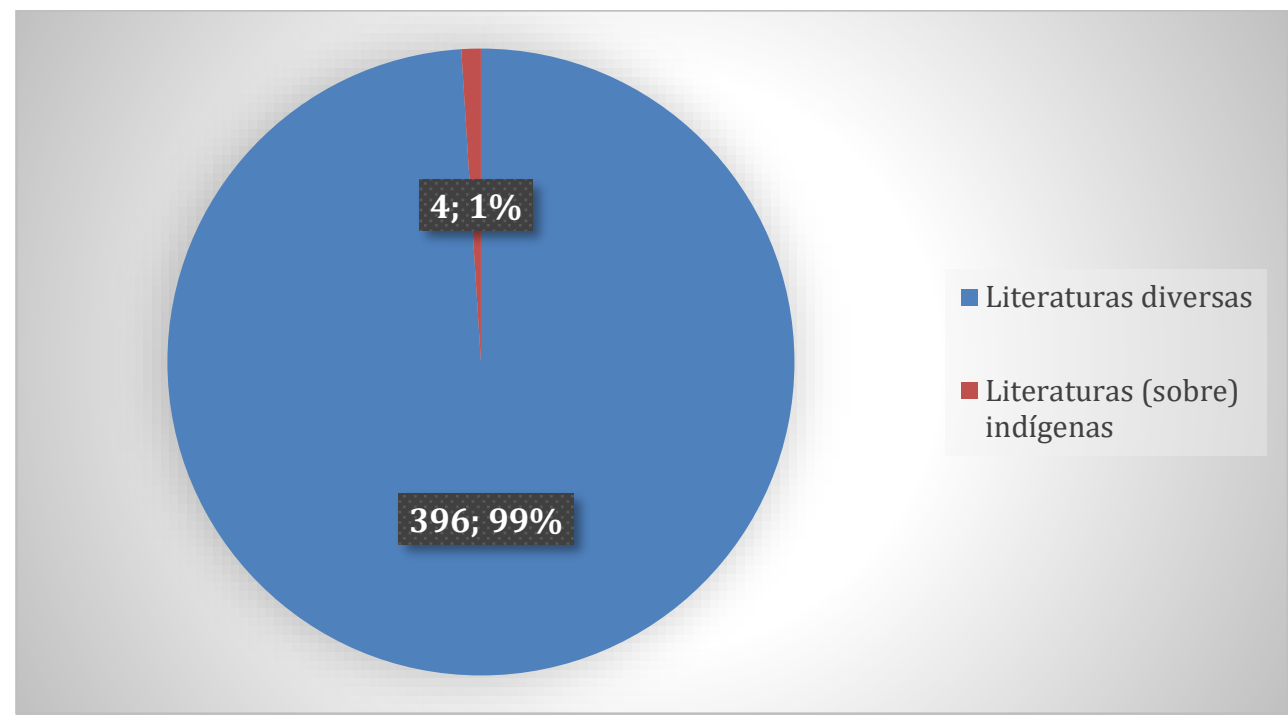

Fonte: elaboração própria a partir das provas aplicadas no período investigado.

$\mathrm{Na}$ seção seguinte, analisamos de que forma tais questões que fazem referência à literatura indígena foram apresentadas nas edições do Enem 2008, 2015 e 2017. Para isso, recorremos tanto aos próprios documentos/dispositivos estatais que "garantem" o ensino desta literatura no âmbito escolar, quanto a estudiosas/os sobre esta literatura. 
4 "Acho que educar é como catar piolho na cabeça de criança": análise da única questão que menciona um escritor indígena em provas do Enem (2008-2019)

Em 2008, ano de sanção à Lei $n^{\circ} 11.645$, o Enem apresentou duas questões a partir do texto "A Ema". Realizamos, portanto, uma análise de tais questões (Figura 1).

Figura 1 - Questões sobre narrativas indígenas na prova do Enem (2008)

Texto para as questöes 1 e 2

\section{A Ema}

O surgimento da figura da Ema no céu, ao leste, no anoitecer, na segunda quinzena de junho, indica o início do inverno para os índios do sul do Brasil e o começo da estação seca para os do norte. É limitada pelas constelações de Escorpião e do Cruzeiro do Sul, ou Cut'uxu. Segundo o mito guarani, o Cut'uxu segura a cabeça da ave para garantir a vida na Terra, porque, se ela se soltar, beberá toda a água do nosso planeta. Os tupisguaranis utilizam o Cut'uxu para se orientar e determinar a duração das noites e as estações do ano.

A ilustração a seguir é uma representação dos corpos celestes que constituem a constelação da Ema, na percepção indígena.

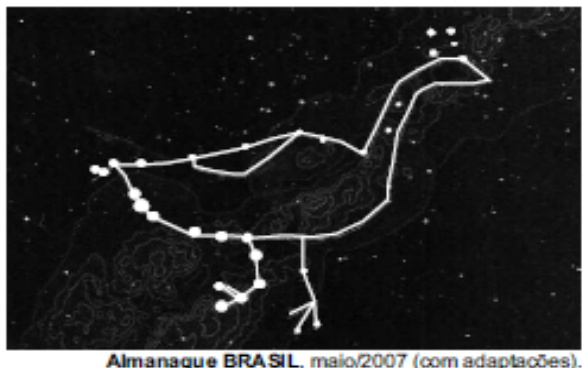

A próxima figura mostra, em campo de visăo ampliado, como povos de culturas não-indigenas percebem o espaço estelar em que a Ema é vista.

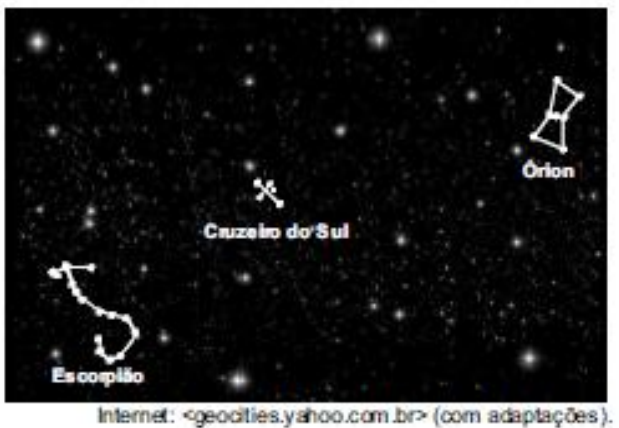




\section{Quesț̄o 1}

Considerando a diversidade cultural focalizada no texto e nas figuras acima, avalie as seguintes afirmativas.

I A mitologia guarani relaciona a presença da Ema no firmamento às mudanças das estações do ano.

II Em culturas indígenas e não-indígenas, o Cruzeiro do Sul, ou Cut'uxu, funciona como parâmetro de orientação espacial.

III Na mitologia guarani, o Cut'uxu tem a importante função de segurar a Ema para que seja preservada a água da Terra.

IV As três Marias, estrelas da constelação de Órion, compõem a figura da Ema.

É correto apenas o que se afirma em
( I.
(B) II e III.
$\odot$ III e IV.
(1) I, II e III.
() I, II e IV.

Questä० 2

Assinale a opção correta a respeito da linguagem empregada no texto A Ema.

- A palavra Cut'uxu é um regionalismo utilizado pelas populações próximas às aldeias indigenas.

B $\mathrm{O}$ autor se expressa em linguagem formal em todos os períodos do texto.

( ) A ausência da palavra Ema no início do período "É limitada (....)" caracteriza registro oral.

(1) A palavra Cut'uxu está destacada em itálico porque integra o vocabulário da linguagem informal.

(3) No texto, predomina a linguagem coloquial porque ele consta de um almanaque.

Fonte: Caderno de Prova Amarelo do Enem 2008 (único dia).

Sob a perspectiva da natureza constituinte da literatura indígena, a qual faz uso da escrita para materializar os aspectos da oralidade e da ancestralidade, a questão poderia apresentar relevantes aspectos ao abordar a astronomia tupi-guarani. Fazemos uso do tempo condicional - poderia, porque importantes narrativas foram silenciadas no texto acima.

No que tange à $\mathrm{BNCC}$, é no $6^{\circ}$ e $7^{\circ}$ anos do ensino fundamental que se prioriza como habilidade a leitura e compreensão "dos gêneros e suportes -, romances infanto-juvenis, contos populares, contos de terror, lendas brasileiras, indígenas e africanas, narrativas de aventuras, narrativas de enigma, mitos, etc. (BRASIL, 2017, p. 165). [Grifos nossos]. No caso da prova do Enem, que tem como público-alvo concluintes (ou que já concluíram o) do ensino médio, reduzir os sofisticados conhecimentos astronômicos dos tupi-guarani à condição de mitologia é silenciar as tecnologias desenvolvidas por estes sujeitos no que diz respeito à compressão do universo e suas relações de causa e efeito entre a lua e as marés, dinâmica esta, notada por estes 
povos, bem antes que os europeus tivessem chegado à conclusão deste fenômeno (AFONSO, 2013), por exemplo.

Além do mais, consideramos que esta materialidade textual não se constitui enquanto literatura indígena, por vários motivos, dentre os quais, podemos destacar: a) por mais que tenha apresentado um elemento que atravessa a literatura indígena, as narrativas orais e sua importância para a compreensão da astronomia no cotidiano de sociedades indígenas guaranis, o texto não apresenta o lugar de fala de sujeitos indígenas, sequer é mencionada a autoria da questão; b) entre tantos aspectos importantes para discussão e reflexão sob o viés literário, a segunda questão prefere se preocupar quanto ao aspecto formal da língua portuguesa, em que se exige que seja assinalada a opção correta a respeito da linguagem, tendo como resposta oficial: "O autor se expressa em linguagem formal em todos os períodos do texto". Após sete anos, as narrativas indígenas são relembradas, neste caso, na prova do Enem 2015 (Figura 2):

Figura 2 - Questão sobre narrativas indígena na prova do Enem (2015).

QUESTÃO $106 \propto \infty \propto \infty \Longleftarrow$

As narrativas indígenas se sustentam e se perpetuam por uma tradição de transmissão oral (sejam as histórias verdadeiras dos seus antepassados, dos fatos e guerras recentes ou antigos; sejam as histórias de ficção, como aquelas da onça e do macaco). De fato, as comunidades indigenas nas chamadas "terras baixas da América do Sul" (o que exclui as montanhas dos Andes, por exemplo) não desenvolveram sistemas de escrita como os que conhecemos, sejam alfabéticos (como a escrita do português), sejam ideogramáticos (como a escrita dos chineses) ou outros. Somente nas sociedades indígenas com estratificação social (ou seja, já divididas em classes), como foram os astecas e os maias, é que surgiu algum tipo de escrita. A história da escrita parece mesmo mostrar claramente isso: que ela surge e se desenvolve - em qualquer das formas - apenas em sociedades estratificadas (sumérios, egípcios, chineses, gregos etc.). O fato é que os povos indígenas no Brasil, por exemplo, não empregavam um sistema de escrita, mas garantiram a conservação e continuidade dos conhecimentos acumulados, das histórias passadas e, também, das narrativas que sua tradição criou, através 
da transmissão oral. Todas as tecnologias indigenas se transmitiram e se desenvolveram assim. $E$ não foram poucas: por exemplo, foram os índios que domesticaram plantas silvestres e, muitas vezes, venenosas, criando o milho, a mandioca (ou macaxeira), o amendoim, as morangas e muitas outras mais (e também as desenvolveram muito; por exemplo, somente do milho criaram cerca de 250 variedades diferentes em toda a América). D'ANGEUS, W. R. Historlas dos Indlos la em casa: narrattvas holgenas e tradiçắo oral popular
no Brasl. Disponivel em: wwW.portakaingang.org. Acesso em: 5 dez. 2012.

A escrita e a oralidade, nas diversas culturas, cumprem diferentes objetivos. $O$ fragmento aponta que, nas sociedades indígenas brasileiras, a oralidade possibilitou

A a conservação e a valorização dos grupos detentores de certos saberes.

B a preservação e a transmissão dos saberes e da memória cultural dos povos.

C a manutenção e a reprodução dos modelos estratificados de organização social.

( ) a restrição e a limitação do conhecimento acumulado a determinadas comunidades.

(૯) o reconhecimento e a legitimação da importância da fala como meio de comunicação.

Fonte: Caderno de Prova Amarelo $2^{\circ}$ dia do Enem 2015.

A materialidade textual em questão, se apresenta como mais completa que as questões propostas pela edição do Enem 2018. Nesta prova do ano 2015, temos a referência de autoria, um notável pesquisador das sociedades indígenas brasileiras, e para além disso, o texto faz referência a importante elemento que constitui a literatura indígena: a oralidade. Assim, por mais que a questão não trate de um texto literário indígena, consideramos ser positiva a reflexão proposta acerca da oralidade enquanto preservação e a transmissão dos saberes e da memória cultural e ancestral das sociedades indígenas.

Desta forma, apresentamos a única questão que menciona um escritor indígena nos últimos 12 anos de existência do Enem (Figura 3), em específico, a edição Enem PPL do ano 2017.

Figura 3 - Única questão que menciona escritor indígena em provas do Enem (2008-2019).

\section{QUESTÃO 30}

Acho que educar é como catar piolho na cabeça de criança.

É preciso ter confiança, perseverança e um certo despojamento.

É preciso, também, conquistar a confiança de quem se quer educar, para fazê-lo deitar no colo e ouvir histórias.

MUNDURUKU, D. Disponivel em: http:I/caravanamekukradja.blogspot.com.br. Acesso em: 5 dez. 2012 
Concorrem para a estruturação e para a progressão das ideias no texto os seguintes recursos:
(A) Comparação e enumeração.
B Hiperonímia e antonímia.
C Argumentação e citação.
(D) Narração e retomada.
() Pontuação e hipérbole.

Fonte: Caderno de Prova Branco 1 dia do Enem PPL 2017.

A única questão a mencionar um escritor indígena nos últimos 12 anos de Enem não tencionou o real significado da literatura indígena. Utilizar um potente texto de um renomado escritor indígena para tratar de questões meramente linguística é reduzir o que pode a literatura. É reduzir as próprias recomendações da Matriz de Referências do Enem no que diz respeito ao que se espera do aluno. Na questão acima não há como estabelecer relações entre a literariedade textual com o momento de sua produção. Não há reflexões que situem os aspectos do contexto histórico, social e político de constituição de sua escrita. Não há informações sobre as concepções e potencialidades artísticas nem procedimentos de construção do texto literário.

Portanto, a única questão a envolver um escritor indígena não potencializa a literatura indígena. Questionar tão somente qual é o recurso de estrutura e progressão de ideias em dado texto literário prescinde do caráter literário e sua potencialidade, isto é, poderia ser respondido sem que o aluno tivesse "degustado" os elementos que constituem a literatura indígena. Apresentar um autêntico texto literário sem relacioná-lo às suas condições de produção, ao seu contexto estético, à sua constituição literária é reduzi-lo à condição de pretexto para abordagens meramente linguísticas. Importa citar que outras materialidades textuais literárias não tiveram o mesmo tratamento na referida edição do Enem, como os exemplos a seguir (Figuras 4, 5 e 6):

Figura 4 - Questão sobre a literatura de João Cabral de Melo Neto.

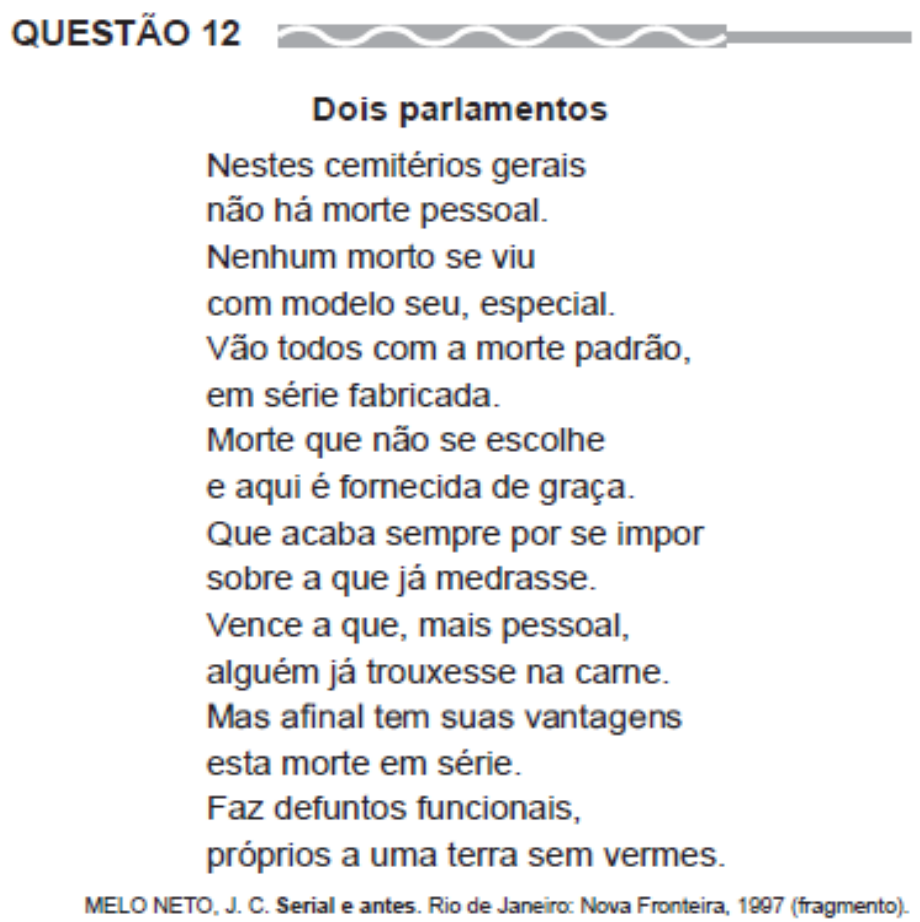


A lida do sertanejo com suas adversidades constitui um viés temático muito presente em João Cabral de Melo Neto. No fragmento em destaque, essa abordagem ressalta o(a)

(A) inutilidade de divisão social e hierárquica após a morte.

B aspecto desumano dos cemitérios da população carente.

C nivelamento do anonimato imposto pela miséria na morte.

D tom de ironia para com a fragilidade dos corpos e da terra.

$\boldsymbol{\Theta}$ indiferença do sertanejo com a ausência de seus próximos.

Fonte: Caderno de Prova Branco 1º dia do Enem PPL 2017.

Figura 5 - Questão sobre a literatura de Vinicius de Moraes.

\section{QUESTÃO 14}

\section{O exercício da crônica}

Escrever prosa é uma arte ingrata. Eu digo prosa fiada, como faz um cronista; não a prosa de um ficcionista, na qual este é levado meio a tapas pelas personagens e situações que, azar dele, criou porque quis. Com um prosador do cotidiano, a coisa fia mais fino. Senta-se diante de sua máquina, acende um cigarro, olha através da janela e busca fundo em sua imaginação um fato qualquer, de preferência colhido no noticiário matutino, ou da véspera, em que, com as suas artimanhas peculiares, possa injetar um sangue novo.

MORAES, V. Para viver um grande amor: crónicas e poemas. Säo Paulo: Cia. das Letras, 1991

Nesse trecho, Vinicius de Moraes exercita a crônica para pensá-la como gênero e prática. Do ponto de vista dele, cabe ao cronista
A criar fatos com a imaginação.
B reproduzir as notícias dos jornais.
C escrever em linguagem coloquial.
D construir personagens verossímeis.
(G) ressignificar o cotidiano pela escrita.

Fonte: Caderno de Prova Branco $1^{\circ}$ dia do Enem PPL 2017. 
Figura 6 - Questão sobre a literatura de Lima Barreto.

\section{QUESTÃO 31}

Chamou-me o bragantino e levou-me pelos corredores e pátios até ao hospício propriamente. Aí é que percebi que ficava e onde, na seção, na de indigentes, aquela em que a imagem do que a Desgraça pode sobre a vida dos homens é mais formidável. O mobiliário, o vestuário das camas, as camas, tudo é de uma pobreza sem par. Sem fazer monopólio, os loucos são da proveniência mais diversa, originando-se em geral das camadas mais pobres da nossa gente pobre. São de imigrantes italianos, portugueses e outros mais exóticos, são os negros roceiros, que teimam em dormir pelos desvãos das janelas sobre uma esteira esmolambada e uma manta sördida; são copeiros, cocheiros, moços de cavalariça, trabalhadores braçais. No meio disto, muitos com educação, mas que a falta de recursos e proteção atira naquela geena social.

BARRETO, L. Diário do hospício e O cemitério dos vivos. São Paulo: Cosac \& Naify, 2010.

No relato de sua experiência no sanatório onde foi interno, Lima Barreto expõe uma realidade social e humana marcada pela exclusão. Em seu testemunho, essa reclusão demarca uma

(A) medida necessária de intervenção terapêutica.

B forma de punição indireta aos hábitos desregrados.

C compensação para as desgraças dos indivíduos.

(D) oportunidade de ressocialização em um novo ambiente.

$\boldsymbol{\Theta}$ conveniência da invisibilidade a grupos vulneráveis e periféricos.

Fonte: Caderno de Prova Branco 1º dia do Enem PPL 2017.

Neste sentido, quando realizamos comparações sobre a forma de tratamento dado às textualidades literárias de João Cabral de Melo Neto, Vinicius de Moraes e Lima Barreto, para citar alguns exemplos, verificamos que a abordagem valoriza o caráter estético-literário. As três questões mencionam os nomes dos autores relacionando-os às suas condições de produções. Enquanto os exemplos tematizam os valores sociais e humanos inerentes à natureza do fazer literário, no texto de Daniel Munduruku (Figura 3) está evidente que sua utilidade serve como pretexto para abordar questões do aspecto linguístico. A textualidade literária tem uma especificidade e um valor que precisam ser preservados. Desta forma, o texto de Munduruku está na mesma condição de um anúncio publicitário, um outdoor, ou até mesmo, uma piada, por exemplo. Enfim, por mais, que se trate de um texto produzido por um escritor indígena, somos levados a afirmar que os aspectos da literatura indígena não foram abordados, possibilitando-nos a refletir que o $1 \%$ que consta no gráfico 01 , certamente, ainda vaga pela casa do zero.

\section{Considerações Finais}

Os resultados apontados neste trabalho lançam luz sobre algumas facetas do Estado quando operam a lógica da colonialidade: revelam práticas de silenciamento de saberes dos povos originários no maior exame nacional da educação brasileira, o Enem. Ao mesmo tempo, apresentam algumas das estratégias de reação por parte desses sujeitos na contemporaneidade: 
passados mais de 520 anos desde a invasão, várias(os) intelectuais indígenas fazem uso da escrita literária enquanto ferramenta de enunciação da ancestralidade e resistência.

Oportunamente, verificamos o lugar da literatura indígena nas provas do Enem desde o advento da Lei $\mathrm{n}^{\circ} 11.645 / 08$. Por mais que esta lei ofereça uma posição de destaque à literatura produzida por indígenas - quando do cumprimento da temática "História e cultura afrobrasileira e indígena" no âmbito escolar - no que diz respeito ao ensino médio, quando consideramos o que preconizam os documentos educacionais sobre o ensino e aprendizagem das expressividades das linguagens por meio das literaturas brasileiras (BNCC, por exemplo), compreendemos que a tímida presença da produção literária indígena no currículo escolar reflete o quanto a aparição dessa literatura em provas do Enem é insuficiente.

Por conseguinte, constatamos que, o percentual da materialidade textual literária indígena não chega nem a meio por cento em um total de 400 questões sobre literatura nas 24 provas da área de conhecimento Linguagens, Códigos e suas Tecnologias. A única questão a mencionar a escrita de um autor indígena [Daniel Munduruku] não cumpriu o caráter literário em sua essência.

Assim, podemos concluir que, no âmbito escolar, mesmo com a "força" da Lei $\mathrm{n}^{\circ}$ 11.645/08, a literatura indígena chega de maneira um tanto quanto tímida ou insuficiente. A ausência da voz indígena por meio da literatura no maior e mais importante exame nacional de avaliação da qualidade do ensino médio brasileiro e porta de acesso para $90 \%$ das instituições de ensino superior públicas nos permite a questionar sobre o direito à literatura (CANDIDO, 2004) em suas variadas frentes.

Os 12 anos desde a promulgação da lei que garante essa voz na escola - mas amplamente omitida no Enem - tão somente ratificam as práticas discursivas de dominação e da alienação intelectual que constituem efeitos de sentido de apagamento e, principalmente, de silenciamento. É nessa perspectiva que o discurso colonial (e dito nacionalista) opera e constitui significados.

\section{Referências}

ABAURRE, Maria Luiza; ABAURRE, Maria Bernadete; PONTARA, Marcela. Português, contexto, interlocução e sentido. São Paulo: Moderna, 2010. v. 2.

AFONSO, Germano. Mitos e Estações no Céu Tupi-Guarani. Scientific American Brasil, v. 14, p. 46-55, 2006. Disponível em: https://bit.ly/31I8oey. Acesso em: 29 ago, 2020.

BRASIL. Ministério da Educação. Conselho Nacional de Educação. Resolução n ${ }^{\circ}$ 2, de 22 de dezembro de 2017. Institui e orienta a implantação da Base Nacional Comum Curricular, a ser respeitada obrigatoriamente ao longo das etapas e respectivas modalidades no âmbito da Educação Básica. Diário Oficial [da] República Federativa do Brasil: seção 1, Brasília, DF, ano 154, n. 245, p. 41, 22 dez. 2017. Disponível em: https://bit.ly/33NgMrU. Acesso em: 20 ago. 2020.

BRASIL. Ministério da Educação. Gabinete do Ministro. Portaria nº 438, de 28 de maio de 1998. Institui o Exame Nacional do Ensino Médio. Diário Oficial [da] República

Federativa do Brasil: seção 1, Brasília, DF, ano 135, n. 102-E, p. 5, 1 jun. 1998. Disponível em: https://bit.ly/3jybJTO. Acesso em: 20 ago. 2020. 
BRASIL. Ministério da Educação. Instituto Nacional de Estudos e Pesquisas Educacionais Anísio Teixeira (INEP). Edital no 25, de 30 de março de 2020 Exame Nacional do Ensino Médio - Enem 2020 impresso. Diário Oficial [da] República Federativa do Brasil: seção 3, Brasília, DF, ano 158, n. 62, p. 33-47, 31 mar. 2020. Disponível em: https://bit.ly/2YRVLf6. Acesso em: 20 ago. 2020.

BRASIL. Ministério da Educação. Instituto Nacional de Estudos e Pesquisas Educacionais Anísio Teixeira (INEP). Matriz de Referência Enem. Brasília. 2020. Disponível em: https://bit.ly/32HapqS. Acesso em: 20 ago. 2020.

BRASIL. Presidência da República. Lei no 11.645 , de 10 de março de 2008. Altera a Lei ${ }^{\circ}$ 9.394, de 20 de dezembro de 1996, modificada pela Lei $\mathrm{n}^{\circ} 10.639$, de 9 de janeiro de 2003, que estabelece as diretrizes e bases da educação nacional, para incluir no currículo oficial da rede de ensino a obrigatoriedade da temática "História e Cultura Afro-Brasileira e Indígena". Diário Oficial [da] República Federativa do Brasil: seção 1, Brasília, DF, ano 145, n. 48, p. 1, 11 mar. 2008. Disponível em: https://bit.ly/2Hj5tRQ. Acesso em: 20 ago. 2020.

CANDIDO, Antonio. O direito à literatura. In: CANDIDO, Antonio. Vários escritos. Rio de Janeiro: Ouro sobre Azul, 2004. p. 169-191.

DORRICO, Julie et al. Considerações iniciais. In: DORRICO, Julie; DANNER, Leno Francisco; CORREIA, Heloisa Helena Siqueira; DANNER, Fernando (org.) Literatura indígena brasileira contemporânea: criação, crítica e recepção. Porto Alegre: Editora Fi, 2018.

GIL, Antônio Carlos. Como elaborar projetos de pesquisa. 4. ed. São Paulo: Atlas, 2007.

GRAÚNA, Graça. Contrapontos da literatura indígena contemporânea no Brasil. 2. ed., Belo Horizonte: Mazza Edições, 2013.

MUNDURUKU, Daniel. Literatura indígenas e as novas tecnologias da memória. In: MARTINS, Maria Sílvia Cintra (org.). Ensaios em interculturalidade literatura, cultura e direitos de indígenas em épocas de globalização. Campinas: Mercado de Letras, 2014.

PÁDUA, Elisabete Matallo Marchesini de. Metodologia da pesquisa: abordagem teóricoprática. 2. ed. Campinas: Papirus, 1997.

PONTES, Vânia Glauciene Gurgel. O Romantismo brasileiro e as reflexões de José de Alencar. Revista Sociopoética, Campina Grande, v. 1, n. 20, p.128-139, jan.-jun. 2018.

ROMERO, Francisco Javier. La literatura indígena mexicana en búsqueda de una identidad nacional. 2010. In: DORRICO, Julie; DANNER, Leno Francisco; CORREIA, Heloisa Helena Siqueira; DANNER, Fernando (org.) Literatura indígena brasileira contemporânea: criação, crítica e recepção. Porto Alegre: Editora Fi, 2018.

Recebido em agosto de 2020.

Aprovado em novembro de 2020. 